\title{
Uji Lethal Concentration (LC) Senyawa Cyanida pada Karang Tingkat Laboratatorium dalam Kaitannya sebagai Bahan Penangkap Ikan Hias
}

\author{
Chrisna Adhi Suryono \\ Jurusan Ilmu Kelautan, Fakultas Perikanan dan Ilmu Kelautan, Universitas Diponegoro \\ JI. Prof. Soedarto, SH. Kampus UNDIP Tembalang, Semarang 50275 \\ Email : chrisna_as@yahoo.com
}

\begin{abstract}
Abstrak
Salah satu cara menagkap ikan hias yang efektip adalah dengan cara membius dengan menggunakan cyanida. Tujuan dari penelitian ini adalah untuk mengetahui letathal concetration senyawa cyanida terhadap karang Porites lutea dan Galaxea fascicularis. Rancangan penelitian yang digunakan adalah split plot RAK dengan ulangan 3 kali. Jenis karang merupakan kelompok utama dan konsentrasi cyanida merupakan sub-kelompok. Pengamatan yang diamati adalah jumlah zooxanthellae dan prosentase kematian karang. Hasil penelitian menunjukan semakin tinggi konsentrasi cyanida menunjukan semakin tinggi prosentase kematian karang. Demikain pengaruhnya terhadap zooxanthellae, semakin tinggi konsentrasi cyanida semakin kecil jumlah zooxanthellae pada karang. Hasil uji anova terhadap tingkat kematian karang dan jumlah zooxanthellae.menunjukan pengaruh yang sangat nyata $(\mathrm{P}<0,001)$.
\end{abstract}

Kata kunci : Cyanida, LC, karang, dan ikan hias

\begin{abstract}
One of the most effective to capture ornamental fishes by using cyanide unconscious. The purpose of this study was to conduct LC of cyanide compound on coral Porites lutea and Galaxea fascicularis. The split plot randomized block design with 3 replicate was use on this study. While the kind of corals as the main block and the cyanide concentration as the subblock. The study focusing on the analyzed of the number of zooxanthellae and the percentage mortality of corals. The results of the study shows, increasing cyanide concentration affected increasing percentage mortality of coral and decreasing the number of zooxanthellae on the coral. The result of ANOVA test showed highly differences significantly $(p<0.001)$.
\end{abstract}

Keywords: Cyanide, LC, coral and artistic fishes

\section{PENDAHULUAN}

Terumbu karang merupakan salah satu sumberdaya hayati laut yang memiliki pesona karena kekayaan dan keanekaragaman yang paling lengkap di dunia, disamping sistem mangrove dan lamun Sukarno (1995). Namun dengan semakin meningkatnya akan permintaan ikan hias laut memacu para penangkap ikan hias menangkap dengan menggunakan cyanida untuk mebiusnya. Karena cyanida merupakan salah satu cara paling efektip untuk menagkap ikan hias. Seperti telah kita ketahui cyanida merupakan racun bagi lingkungan dan sangat toksik terhadap karang bila telah berikatan dengan logam logam yang berada di perairan seperti Ni, CU, Zn dan Fe.

Daya toksisitas senyawa ini untuk organisme yang hidup dalam perairan dalam bentuk hidrolitik cyanida yang bereaksi dengan air (Greenberg et al., 1985). Lebih lanjut Supriyanto dan Sabdono 
(1995) melaporkan hasil penelitiannya tentang pengaruh $\mathrm{NaCN}$ pada karang Porites sp dan Galaxea sp di Teluk Awur, menunjukkan bahwa senyawa cyanida dapat membunuh karang pada konsentrasi yang rendah dalam waktu yang singkat.

Penelitian pengaruh cyanida terhadap karang masih sedikit dilakukan hanya ada beberapa penelitian tentang degradasi senyawa tersebut pada limbah buangan oleh beberapa strain bakteri (Boucabeille, 1994). Demikian pula dengan hasil penelitian yang dilaporkan Carballo dkk (1995) yang menunjukkan bahwa cyanida dan nitrit memberi pengaruh yang nyata terhadap kekebalan ikan Trout (Oncorhynchus mykiss).

Namun demikian penangkapan ikan hias masih terus dilakuakan dengan cara membius menggunakan cyanida. Dari informasi diatas yang mengatakan bahwa cyanida merupakan senyawa yang berbahaya bagi organisme perairan terutama karang. Karena karang merupakan organisme yang menetap diperairan dan dijadikan tempat hidup bagi ikan hias. Jadi dengan adanya penangkapan ikan hias dengan menggunakan cyanida tentunya akan memberi dampak yang sangat nyata terhadap karang tersebut. Maka dari itu tujuan dari penelitian ini adalah untuk mengetahui toksisitas senyawa cyanida terhadap karang.

\section{MATERI DAN METODE}

Materi yang digunakan dalam penelitian adalah karang Porites lutea dan karang Galaxea fascicularis yang berasal dari Pulau Karimunjawa, Jepara.

Uji pendahuluan untuk menentukan nilai ambang atas dan bawah dilakukan dengan cara meletakkan 3 buah sampel karang pada bak-bak akuarium yang berisi larutan cyanida dengan konsentrasi yang berbeda secara geometris berbasis $10\left(10^{-2}\right.$ ; $10^{-1} ; 10^{0} ; 10^{1} ; 10^{2} ; 10^{3}$ ppm NaCN dan kontrol). Pengamatan dilakukan selama 48 jam dengan interval 15'; 30 ' ; 1 jam; 2 jam; 4 jam; 8 jam; 16 jam; 24 jam dan 48 jam untuk melihat karang yang 'bleaching'.

Uji utama LC cyanida terhadap karang dilakukan dengan cara meletakkan sampel-sampel karang (5 buah) pada bak akuarium yang berisi larutan herbisida dengan konsentrasi yang berbeda (7 interval antara nilai ambang atas dan ambang bawah). Pengamatan dilakukan selama 48 jam dengan interval 15'; 30'; 1 jam; 2 jam; 4 jam; 8 jam; 16 jam; 24 jam dan 48 jam untuk melihat karang yang 'bleaching'. Pengamatan kepadatan zooxanthellae dilakukan dengan alat Sedwick rafter dibawah mikroskup yang dihitung dengan menggunakan rumus :

$$
N=T / L \times P / P \times V / V \times 1 / W
$$

dimana :

$\mathrm{N}$ : jumlah zooxanthellae tiap satuan luas,

$\mathrm{L}$ : luas gelas penutup (mm2),

$\mathrm{p}$ : jumlah plankton yang tercacah,

$P$ : jumlah lapang pandang yang diamati,

$\checkmark$ : volume air sampel dalam bucket ( $\mathrm{ml})$,

$\checkmark$ : volume air sampel dalam gelas penutup (ml),

$W$ : luas permukaan karang yang diamati.

Rancangan yang digunakan adalah Split Plot RAK dengan ulangan 3 kali. Jenis karang merupakan petak utama dan konsentrasi cyanida merupakan anak petak. Pengamatan meliputi jumlah mortalitas karang, jumlah zooxanthella dan prosentase bleaching . Data yang diperoleh akan dianalisa dengan menggunakan Proc SAS GLM dan Analisa probit dari Hubert.

\section{HASIL DAN PEMBAHASAN}

Hasil uji pendahuluan senyawa cyanida terhadap karang dapat dilihat pada Tabel 1.

Dari Tabel 1 dapat dilihat bahwa karang mengalami reaksi yang sangat dramatis terhadap senyawa cyanida. Thompson et al. (1980) mengatakan 
bahwa stres pada karang dapat dilihat pada tentakelnya, yaitu: karang menarik tentakel sedalam-dalamnya ke dalam koralit, karang menarik tentakelnya secara penuh dan seluruh tentakel karang dikeluarkan secara maksimal melebihi Ukurannya. Namun pada karang P. Iutea reaksi dari tentakel tidak terlihat jelas karena ukuran tentakelnya yang terlalu kecil. Hasil uji pendahuluan menunjukkan konsentrasi ambang bawah (LC0-48 jam) untuk karang $G$. fascicularis dan $P$. lutea adalah 10 ppm, serta konsentrasi ambang atas untuk ke dua jenis karang tersebut adalah sebesar 100 ppm. Dari nilai tersebut diperoleh nilai deret konsentrasi yang digunakan di dalam uji utama adalah 13,89 ppm; 19,31 ppm; 26,83 ppm; 37,28 ppm; 51,79 ppm; 71,97 ppm dan 100 ppm.

Hasil analisis pengaruh cyanida terhadap mortalitas karang dan jumlah zooxanthellae dapat dilihat pada Tabel 2, 3, 4, 5 dan 6 serta Gambar 1 dan 2.

Tabel 1. Pengaruh senyawa cyanida terhadap karang P. lutea dan G. Fascicularis

\begin{tabular}{|c|c|c|}
\hline \multirow{2}{*}{ No. } & \multicolumn{2}{|c|}{ Reaksi karang } \\
\hline & P. lutea & G. fascicularis \\
\hline 1. & Terbetuk mukus & Menarik tentakel ke dalam koralit \\
\hline 2. & Warna memudar coklat ke kuning & Terbentuk lendir dan warna memudar \\
\hline 3. & Warna kuning ke abu-abu & Jaringan terkelupas \\
\hline 4. & Warna putih - mati & Mati \\
\hline
\end{tabular}

Tabel 2. Hasil anova toksisitas cyanida terhadap mortalitas karang

\begin{tabular}{lccccccc}
\hline \multicolumn{1}{c}{ Sumber Variasi } & db & JK & KT & F-hit & \multicolumn{2}{c}{ F-tabel } \\
\cline { 7 - 8 } & & & & & $5 \%$ & $1 \%$ \\
\hline $\begin{array}{l}\text { Petak Utama: } \\
\text { Ulangan }\end{array}$ & 2 & 2016,67 & 1008,33 & 3,12 & 19,0 & 99,0 \\
$\begin{array}{l}\text { Jenis karang (S) } \\
\text { Galat acak (a) }\end{array}$ & 1 & 0 & 0 & 0 & 18,51 & 98,49 \\
\hline Anak petak: & 2 & 650 & 325 & & & \\
Konsentrasi (K) & 7 & 43033,3 & 6147,62 & $64,55^{* *}$ & 2,36 & 3,36 \\
Interaksi SxK & 7 & 400 & 57,1429 & 0,60 & 2,36 & 3,36 \\
Galat acak (b) & 28 & 2666,67 & 95,2381 & & & \\
\hline Total & 47 & 48766,7 & 1037,59 & & & \\
\hline
\end{tabular}

Tabel 3. Hasil uji tingkat II BNJ 5\% mortalitas karang

\begin{tabular}{ccc}
\hline $\begin{array}{c}\text { Konsentrasi } \\
(\text { ppm) }\end{array}$ & \multicolumn{2}{c}{ Jenis Karang } \\
\cline { 2 - 3 } & G. fascicularis & P. lutea \\
\hline 0 & $0,00 \mathrm{a}$ & $0,00 \mathrm{a}$ \\
13,89 & $33,33 \mathrm{~b}$ & $33,33 \mathrm{~b}$ \\
19,31 & $53,33 \mathrm{c}$ & $46,66 \mathrm{c}$ \\
26,83 & $60,00 \mathrm{c}$ & $53,33 \mathrm{c}$ \\
37,28 & $66,66 \mathrm{~d}$ & $66,66 \mathrm{~d}$ \\
51,79 & $73,33 \mathrm{e}$ & $86,66 \mathrm{e}$ \\
71,97 & $86,66 \mathrm{e}$ & $86,66 \mathrm{e}$ \\
100 & $100,00 \mathrm{f}$ & $100,00 \mathrm{f}$ \\
\hline
\end{tabular}


Tabel 4. Hasil anova toksisitas cyanida terhadap jumlah Zooxanthellae

\begin{tabular}{|c|c|c|c|c|c|c|}
\hline \multirow{2}{*}{ Sumber Variasi } & \multirow{2}{*}{$\mathrm{db}$} & \multirow{2}{*}{$J K$} & \multirow{2}{*}{ KT } & \multirow{2}{*}{ F-hit } & \multicolumn{2}{|c|}{ F-tabel } \\
\hline & & & & & $5 \%$ & $1 \%$ \\
\hline \multicolumn{7}{|l|}{ Petak Utama: } \\
\hline Jenis karang (S) & 1 & 0,0394 & 0,0394 & $60,61^{*}$ & 18,5 & 98,49 \\
\hline Galat acak (a) & 2 & 0,0013 & 0,00065 & & & \\
\hline \multicolumn{7}{|l|}{ Anak petak: } \\
\hline Konsentrasi (K) & 7 & 2,8088 & 0,40127 & $143,3^{* *}$ & 2,36 & 3,36 \\
\hline Interaksi SxK & 7 & 0,1903 & 0,0271 & $9,6^{* *}$ & 2,36 & 3,36 \\
\hline Galat acak (b) & 28 & 0,0799 & 0,0028 & & & \\
\hline Total & 47 & 3,1369 & & & & \\
\hline
\end{tabular}

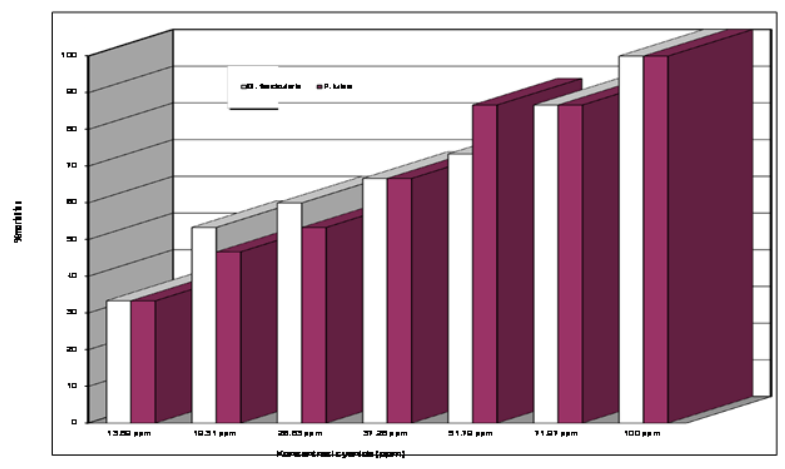

Gambar 1. Pengaruh konsentrasi cyanida terhadap \% mortalitas karang

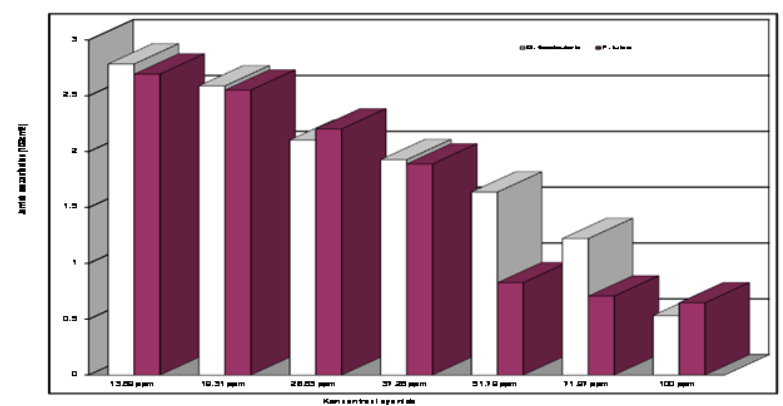

Gambar 2. Pengaruh konsentrasi cyanida terhadap jumlah zooxanthellae $\left(106 / \mathrm{cm}^{2}\right)$ 
Tabel 5. Hasil uji tingkat II BNJ 5\% jumlah Zooxanthellae $\left(106 / \mathrm{cm}^{2}\right)$ pada berbagai konsentrasi cyanida

\begin{tabular}{crlll}
\hline \multirow{2}{*}{$\begin{array}{c}\text { Konsentrasi } \\
\text { (ppm) }\end{array}$} & G. fascicularis & Penis Karang \\
\cline { 2 - 5 } & 3,1389 & $\mathrm{a}$ & 3,1258 & $\mathrm{a}$ \\
13,89 & 2,7853 & $\mathrm{ab}$ & 2,6953 & $\mathrm{ab}$ \\
19,31 & 2,5894 & $\mathrm{~b}$ & 2,5521 & $\mathrm{~b}$ \\
26,83 & $2,1045 \mathrm{c}$ & 2,2036 & $\mathrm{bc}$ \\
37,28 & 1,9283 & $\mathrm{~cd}$ & 1,8902 & $\mathrm{c}$ \\
51,79 & 1,6387 & $\mathrm{~d}$ & 0,8278 & $\mathrm{~d}$ \\
71,97 & 1,2221 & $\mathrm{e}$ & 0,7074 & $\mathrm{e}$ \\
100,00 & 0,3525 & $\mathrm{e}$ & 0,6472 & $\mathrm{e}$ \\
\hline
\end{tabular}

Tabel 6. Hasil uji tingkat II BNJ 5\% jumlah Zooxanthellae $\left(106 / \mathrm{cm}^{2}\right)$ pada species karang $P$. lutea dan G. fascicularis

\begin{tabular}{|c|c|c|c|c|c|c|c|c|c|c|}
\hline \multirow{2}{*}{ Karang } & \multicolumn{10}{|c|}{ Konsentrasi cyanida (ppm) } \\
\hline & K & A & B & $\mathrm{c}$ & & $\mathrm{D}$ & & $E$ & $\mathrm{~F}$ & G \\
\hline G.fascicularis & $3.13 a$ & $2.78 a$ & $2.58 \mathrm{a}$ & 2.10 & $a$ & 1.93 & $a$ & $1.64 \mathrm{a}$ & $1.22 \mathrm{a}$ & $0.53 a$ \\
\hline P. lutea & $3.12 a$ & $2.69 a$ & $2.55 \mathrm{a}$ & 2.20 & $a$ & 1.89 & $a$ & $0.83 \mathrm{~b}$ & $0.71 \mathrm{~b}$ & $0.65 a$ \\
\hline
\end{tabular}

Dari tabel-tabel dan gambargambar tersebut terlihat bahwa senyawa cyanida memberikan pengaruh yang sangat nyata terhadap mortalitas karang dan pelepasan zooxanthellae. Jenis karang juga memberikan signifikansi yang nyata pada toleransi/ketahanannya terhadap toksisitas senyawa cyanida. Semakin tinggi konsentrasi senyawa cyanida, akan semakin meningkatkan pelepasan zooxanthellae dari jaringan karang dan mempercepat kematian karang. Hutabarat (1991) mengatakan bahwa faktor-faktor yang mempengaruhi toksisitas bahan beracun terdiri dari faktor biotik dan abiotik (temperatur, salinitas dan oksigen terlarut). Sedangkan Manahan (1992) mengatakan bahwa faktor-faktor yang mempengaruhi toksisitas terdiri dari bentuk atau wujud dari bahan beracun, lamanya terkontaminasi dengan racun dan jenis organisme dan lingkungan yang teracuni. Reaksi stress dari karang dapat dilihat dari produksi mukus disamping pengamatan pada tentakelnya. Heath (1987) mengatakan bahwa produksi mukus dimaksudkan untuk melindungi organ dari zat pengganggu dari luar. Efek lain terlihat dari memudarnya warna karang. Pemudaran warna karang ini disebabkan oleh penurunan jumlah zooxanthellae dari jaringan karang (Hayes dan Bush, 1990; Gates, 1989; Brown dan Ogden, 1993).

Analisis probit menunjukkan bahwa $L_{50-96}$ jam dari karang $G$. fascicularis dan $P$. Iutea adalah sebesar 20,94 ppm dan 21,94 ppm. Nilai dari LC 50-96 jam tersebut termasuk kategori toksisitas lethal sedang (Anonim, 1983). Tingkat daya racun sangat tinggi bila nilai $\mathrm{LC}_{50-96} \mathrm{jam}<1$, tinggi bila nilai $\mathrm{LC}_{50-96} \mathrm{jam}$ antara 1-10, sedang bila nilai $\mathrm{LC}_{50-96}$ jam antara 10-100 dan rendah bila nilai LC 50-96 jam $>100$. Clark (1986) mengatakan bahwa toksisitas merupakan suatu ukuran seberapa daya racun suatu substansi yang dibutuhkan untuk membunuh atau merusak suatu organisme. Semakin banyak substansi yang dibutuhkan untuk daya racun maka semakin rendah tingkat lethal konsentrasinya.

\section{KESIMPULAN}

Berdasarkan hasil penelitian yang diperoleh dapat disimpulkan bahwa: (1) Cyanida dapat membunuh karang dalam konsentrasi yang rendah dan waktu yang singkat. Semakin tinggi konsentrasi 
senyawa cyanida, menyebabkan mortalitas karang yang semakin meningkat, (2) Nilai LC50-96 jam untuk karang $G$. fascicularis sebesar 20,94 ppm, sedangkan nilai LC 50-96 jam untuk karang P. lutea sebesar $21,94 \mathrm{ppm}$.

\section{UCAPAN TERIMAKASIH}

Pada kesempatan ini kami tim peneliti mengucapkan terimakasih kepada Universitas Diponegoro yang telah mebiayai penelitian melalui dana DIK Rutin Universitas Diponegoro, Lembaga Penelitian Universitas Diponegoro yang telah membantu proses administrasi, Fakultas Perikanan dan IImu Kelautan, Jurusan IImu Kelautan dan Laboratorium Ilmu Kelautan di Jepara.

\section{DAFTAR PUSTAKA}

Anonim, 1983. Pedoman Umum pengujian laboratorium toksisitas lethal pestisida pada ikan untuk keperluan pendaftaran. Komisi Pestisida. Departemen Pertanian. Jakarta, 19 hal.

Boucabeille, A., A. Bories, P. Ollivier and G. Michel. 1994. Microbial Degradation of Metal Complexed Cyanides and Thiocyanate from Mining Wastewaters. Environ. Poll. 84 : 59-67 pp.

Brown, B.E. and J.E. Ogden 1993. Coral blesching. Envronmental stresses causes can cause irreparable harm to coral reefs. Unusually high seawater temperatures may be a princible culprit. Scientific American 268: 64-70.

Carballo, M., M.J. Munoz, M. Cuellar and J.V. Tarazona, 1995. Effects of Waterborne Copper, Cyanide,
Ammonia, and Nitrite on Stress Parameters and Changes in Susceptibility to Saprolegniosis in Rainbow Trout (Oncorhynchus mykiss). Appl. and Environ. Microbiol. Vol.61 no.6: $2108-2112$.

Clark, R.B. 1986. Marine pollution. Oxford University Press. New York 215 pp.

Greenberg, A.E., R.R. Trussell, L.S. Clesceri, 1985. Standard Methods. For Examination of Water and Waste water . American Public Health Association. 1015 Fifteenth Street NW, Washinton, DC 20005.

Hayes, R.B. and G. Bush 1990. Microscopic observations of recovery in the reefbuilding scleretanian coral, Montastrea annularis, after bleaching an a Cayman Reef. Coral Reefs 8: 203-209.

Heath, R.L. 1987. Water pollution and fish physiology. C.R.C. Press. Boston. 245 pp.

Hutabarat, J. 1991. Aquatic toxicology. Jurusan Perikanan. Fakultas Peternakan UNDIP. Semarang 20 hal.

Manahan, S.E. 1992. Toxicological chemistry. Second Edition. Lewis publisher Inc. London. $449 \mathrm{p}$.

Sukarno, R. 1995. Ekosistem Terumbu Karang dan Masalah Pengelolaannya. P3OLIPI - UNDIP . Materi Pendidikan dann Pelatihan Metodologi Penelitian Penentuan Kondisi Terumbu Karang. Jepara.

Supriyanto, T dan A. Sabdono, 1995. Pengaruh Apotash terhadap Mortalitas Karang (Porites sp dan Galaxea sp.) di Teluk Awur, Jepara. (tidak dipublikasikan).

Thompson, J.H., A.S. Eugene dan J.B. Thomas 1980. Effects of drilling mud on seven species of reef-building corals as measured in the field and laboratory (Marine Environmental Pollution). Amsterdam: 433-453. 